\title{
Discussion: medical illness and depression
}

\author{
Discussão: doença clínica e depressão
}

\author{
James J. Strain
}

T he comorbidity of medical and psychiatric illness presents many dilemmas for psychiatric diagnosis that have not been sufficiently taken into account in either the Diagnostic and Statistical Manu al of Mental Disorders IV - Text Revision (DSM-IV-TR) or the Tenth Revision of International Classification of Diseases (ICD-10) psychiatric section. These lexicons have not considered the confounds that arise with medical and psychiatric comorbidity. For example, vegetative signs of fatigue, change in appetite (increased or decreased), diminished libido, and sleep disturbances (either hypo or hypersomnia) can accompany medical illness, e.g., cardiac disease, or major affective disorders (MAD). DSM states that if a symptom can be attributable to a medical disease it cannot be enlisted to support a psychiatric diagnosis.

Because it is so difficult to ascertain symptom attribution, the diagnosis of depression in the medically ill is significantly compromised with comorbidity. Symptom origin can be psychological, medical - somatic, pharmacological, mixed - or indeterminate. Comorbidity then means that there are two systems of diagnoses, two genres of medications to be considered, two disciplines of medical doctors, and two systems of patient care.

Since depression is associated with making many medical illnesses worse it is essential that an attempt be made to diagnose this protean disease in the medical setting. For example, it has been shown that depressed patients with a recent myocardial infarction (MI) have a three times greater chance of dying than those who are not depressed with a recent myocardial infarction (Frasure-Smith, 1993). Fifteen percent to $23 \%$ of all MI patients evidence major depression. FrasureSmith reported depression to be a significant predictor of mortality $(p<.001)$ six months following an MI (Frasure-Smith, 1993). Multivariate analysis factored out the effects of left ventricular dysfunction, previous $\mathrm{MI}$, and premature ventricular contractions. Finally, new onset depression had a greater risk than chronic depression as a risk factor to enhance the effects of coronary artery disease. Elevated Beck Depression Inventory scores were a more powerful predictor of mortality in those with > 10 premature ventricular complex (PVC).

Similarly it has been shown that $40 \%$ of patients with a recent cerebral vascular accident (CVA) die within one year, whereas $70 \%$ of those who also have a major affective disorder die within one year (Jorge, 2003). A significant relationship also exits with regard to pathological outcome in the case of diabetes. Depression is associated with poor glycemic control in types 1 and 2 diabetes. Consequently it becomes incumbent that a psychiatric assessment - namely evaluating for depression - should be an integral component of the medical assessment of these vulnerable groups.

Furthermore, it has been presented that depression and perhaps other psychiatric disorders are really systemic

\footnotetext{
Division of Behavioral Medicine and Consultation Psychiatry, Mount Sinai/New York University Medical Center

Recebido

28-02-06

Aprovado

01-03-06

Correspondence to: James J. Strain

Division of Behavioral Medicine and Consultation Psychiatry - Mount Sinai/New York University Medical Center - Box 1230 - New York, NY 10029 - USA - e-mail: jim_strain@hotmail.com
} 
illnesses and should be understood as more far reaching than just a psychiatric entity that stands alone (Strain, 2005; Cowles, 2006). For example, depression stimulates the hypothalamicpituitary-adrenal axis (Nemeroff, 2000). The liberation of cortisol affects platelet activity so that it is enhanced. With enhanced platelet aggregation in a previously damaged vessel, recurrent injury may take place, with reblockage and the recurrence of a CVA or an MI (Figure).

Depression travels with other illnesses (Charney, 2005). The concept that depression is a systemic illness means that knowledge of its diagnosis, treatment, and medical effects should be a part of the curriculum for medicine, in particular primary care, and not just psychiatry. Biological correlates of depression include: 1) sympathoadrenal hyperactivity; 2) diminished heart rate variability (HRV); 3) ventricular instability; 4) myocardial ischemia secondary to mental stress; 5 ) increase of corticotropin-releasing factor (CRF); 6) increased release of corticotropin (ACTH); and 7) increase of beta endorphin (Musselman, 1998).

Every patient in a cardiac care unit with a recent MI should be evaluated for depression and it is mandatory that it be treated to mitigate the chance for a vascular recurrence. Robinson recommends that all patients with a CVA be placed on selective serotonin reuptake inhibitors (SSRIs) to reduce the chance of a recurrence (Jorge, 2003). Therefore, depression is a disorder of medicine and not just a disorder of psychiatry.

\section{Figure. The relationship between major depression and cardiovascular disease}

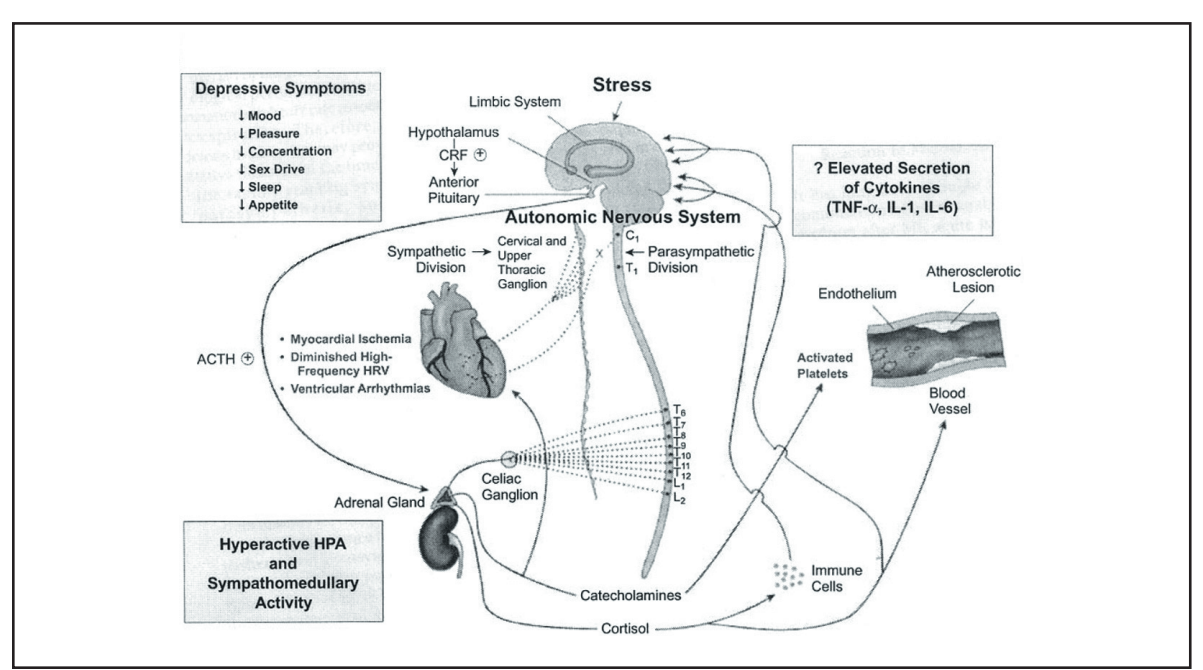

Note: Hypothetical schema of pathophysiologic alterations associated with depression that likely contribute to increased vulnerability to cardiovascular disease (CVD). Autonomic nervous system innervation of the heart via parasympathetic vagus $(X)$ and sympathetic (postganglionic efferents from cervical and upper thoracic paravertebral ganglia) nerves is shown. CRF: corticotropinreleasing factor; ACTH: corticotropin; TNF-a: tumor necrosis factor $\alpha$; IL-1: interleukin 1; IL-6: interleukin 6; HRV: heart rate variability; HPA: hypothalamic-pituitary-adrenocortical axis. From Musselman et al., 1998. Archives of General Psychiatry, 55(7): 580-92, 199; with permission.

\section{References}

Charney D. Personal communication. October, 2005.

Cowles M, Nemeroff CB. Depression: a systemic illness. In: Blumenfield M, Strain JJ. Psychosomatic Medicine. Lippincott, Williams, and Wilkins, Baltimore, 2006.

Frasure-Smith N, Lesperance F, Talajic M. Depression following myocardial infarction: impact of 6-month survival. JAMA, 270(15): 1819-25, 1993

Jorge RE, Robinson RG, Arndt S, Starkstein S. Mortality and post-stroke depression: a placebo-controlled trial of antidepressants. Am J Psychiatry, 160: 1823-9, 2003.

Musselman DL, Evans DL, Nemeroff CB. The relationship of depression to cardiovascular disease: epidemiology, biology, and treatment. Arch Gen Psychiatry, 55(7): 580-92, 1998.

Nemeroff CB, Musselman DL. Are platelets the link between depression and ischemic heart disease? Am Heart J, 140(4): 557-62, 2000.

Strain JJ. Psychiatric diagnostic dilemmas in the medical setting. Aust N Z J Psychiatry, 39(9): 764-71, 2005. 